\title{
EDUCAÇÃO PROFISSIONAL E DESENVOLVIMENTO TERRITORIAL: A EXPANSÃO DOS INSTITUTOS FEDERAIS DE EDUCAÇÃO, CIÊNCIA E TECNOLOGIA
}

\author{
P. C. S. Macedo \\ Instituto Federal de Educação, Ciência e Tecnologia do Amapá \\ pedro.macedo@ifap.edu.br \\ 10.15628/rbept.2017.5821 \\ Artigo submetido em mar/2017 e aceito em ago/2017
}

\section{RESUMO}

O artigo tem por objetivo caracterizar a trajetória inicial dos Institutos Federais de Educação, Ciência e Tecnologia e sua relação com o desenvolvimento territorial, identificando seus impactos na implementação de políticas públicas voltadas para a educação profissional e tecnológica. A pesquisa busca analisar o papel dos Institutos Federais, a partir da Lei 11.892 de 29 de dezembro de 2008, que cria 38 Institutos Federais de Educação, Ciência e Tecnologia e instituiu ainda a Rede Federal de Educação Profissional, Científica e Tecnológica, levando em consideração as finalidades, características e objetivos traçados para esse novo modelo institucional, especialmente no que tange a temática do desenvolvimento regional e territorial, muito destacada no texto legal. O conceito de território foi estudado sob a ótica de vários autores que tratam do tema, para um melhor entendimento no contexto dos dispositivos legais. Para esta investigação, optou-se pela abordagem qualitativa, através de pesquisa bibliográfica e análise documental.

Palavras-Chaves: Institutos Federais, Desenvolvimento Territorial, Educação Profissional.

\begin{abstract}
This article aims to characterize the initial trajectory of the Federal Institutes of Education, Science and Technology and their relation with territorial development, identifying their impacts in the implementation of public policies focused in professional and technological education. Through the law which established 38 Federal Institutes of Education, Science and Technology and also established the Federal Professional Education Network (Law 11,892 / 2008), this research analyzes the role of the Federal Institutes considering their purpose, characteristic and objective traced for this new institutional model, highlighting, in particular, regional and territorial development issues, which is very prominent in the legal text. For a better understanding in the context of legal provisions, the concept of territory was studied from the perspective of several authors who deal with the theme. For this investigation, the qualitative approach was chosen through bibliographic research and documentary analysis.
\end{abstract}

KEYWORDS: Federal Institutes, Territorial Development, Professional Education. 


\section{INTRODUÇÃO}

Esta pesquisa tem como objetivo apresentar estudos sobre a Educação Profissional e Tecnológica no Brasil e sua relação com o desenvolvimento territorial no contexto das políticas de Estado, a partir de reflexões sobre os aspectos legais e teóricos, tais como políticas de educação, trabalho, território e desenvolvimento. Constituindo-se como um importante destaque na política de educação no Brasil, a expansão da Educação Profissional e Tecnológica, traz novas proposições e novos conceitos na busca de respostas às expectativas do mundo do trabalho e da sociedade contemporânea.

Esta investigação está pautada na contextualização histórica, social e política da Educação Profissional no Brasil, evidenciando os marcos principais e as propostas que foram se constituindo até a atual conjuntura, tendo como destaque a Lei de Lei 11.892 de 29 de dezembro de 2008, que cria os Institutos Federais de Educação, Ciência e Tecnologia (IFs).

A característica da pesquisa tem como base a abordagem qualitativa, a partir da utilização de recursos e técnicas de pesquisa bibliográfica e documental. A pesquisa qualitativa encontra uma sustentação em Günther (2006), quando considera que ao invés de utilizar instrumentos e procedimentos padronizados, a pesquisa qualitativa considera cada problema objeto de uma pesquisa específica para a qual são necessários instrumentos específicos.

Os termos território e territorialidade têm sido abordados por diversos teóricos nas mais diversas áreas, e na atualidade, tem se destacado no cenário político e governamental, como conceitos essenciais para a promoção do desenvolvimento local e regional. Portanto, esses referenciais teórico-conceituais se integram aos objetivos da pesquisa sobre a trajetória histórica da Educação Profissional no Brasil, tendo como foco a implantação dos IFs e sua relação com o desenvolvimento territorial.

\section{BREVE TRAJETÓRIA DA EDUCAÇÃO PROFISSIONAL NO BRASIL}

No início do século XXI, a Educação Profissional e Tecnológica no Brasil passou por um momento histórico de constante transformação econômica, política e social. A recente retomada do crescimento econômico do país, mesmo em contramão à crise mundial, o aumento dos investimentos nos chamados mercados emergentes e o avanço das novas tecnologias são fatores que provocam a necessidade de ampliação da formação de profissionais qualificados tendo em vista atender a demanda de uma economia em expansão.

Lefosse (2010) reconstituindo a trajetória histórica da educação profissional relata que esta tem suas origens com a criação do Colégio de Fábricas por D. João VI, no ano de 1809, no Rio de Janeiro. No decorrer do século XIX, inúmeras instituições foram criadas, com a finalidade de promover ensino das primeiras letras e a iniciação em ofícios, instituições destinadas a "amparar as crianças pobres, os órfãos e desvalidos da sorte" (BRASIL, 2007a), isto é, atender àqueles que não tinham condições sociais satisfatórias, evitando assim, a prática de ações contra os bons costumes.

Nessa fase inicial, a educação profissional originou-se predominantemente na sociedade civil e com objetivos assistencialistas, pois o modo de produção desse período, baseado na exploração e na expropriação de matéria-prima destinadas aos países europeus, não exigia mão de obra qualificada, não havendo assim, grandes preocupações com a educação das classes trabalhadoras, em função das tarefas que lhes eram exigidas. (OLIVEIRA, 2012, p. 48). 
Para Oliveira (2012), no período de transição entre os séculos XIX e XX, inicia-se um esforço público de organização da formação profissional, em que se mescla aos fins assistencialistas a preparação de operários para o incipiente processo de industrialização. Esse caráter assistencialista da educação profissional em sua fase inicial é destacado com ênfase por Frigotto:

Quando o ensino profissional no Brasil é analisado surge, num primeiro momento, o indício da organização capitalista, baseada no crescimento industrial com a ideia da escola do trabalho tomando forma de uma ideologia assistencialista com base na ética cristã, pela qual os ricos devem ser generosos com os pobres, dando-Ihes o suficiente para a sobrevivência, posto que a situação de desigualdade é tida como algo dado naturalmente. Essas ideias trazem consigo a necessidade de manutenção das desigualdades, mas, além disso, o trabalho torna-se necessário para uma determinada organização social. (2006, p. 53) [grifo do autor].

Em 1857, também voltado para a aprendizagem de ofícios, instala-se no Rio de Janeiro, a denominada Sociedade Propagadora de Belas Artes, que cria o Liceu de Artes e Ofício, que destinava educação profissional aos jovens em estado de pobreza, onde recebiam instrução primária. Em 1909, foram criadas as Escolas de Aprendizes e Artífices, em 19 estados, por intermédio do Presidente Nilo Peçanha, através do Decreto 7.566 de 23 de setembro de 1906. (WANDERLEY, 2009).

As Escolas de Aprendizes e Artífices, destinadas aos pobres e humildes, expandiuse em todo o território nacional, sendo a primeira rede de educação profissional do Brasil. Em contrapartida, organizou-se o ensino agrícola para capacitar os chefes de cultura, administradores e capatazes, evidenciando um redirecionamento da educação profissional. Assim, seu campo de atuação é ampliado para atender aos interesses econômicos emergentes nos campos da agricultura e da indústria. (OLIVEIRA, 2012, p.49).

Para Frigotto (2006) o ensino das Escolas de Aprendizes e Artífices deveria voltar-se para a formação de operários e contramestres, e estes deveriam estar em condições de atender às exigências da indústria moderna em função da sua instrução, atividade e moral. Antes deste período, a formação profissional se restringia ao treinamento para a produção em série e padronizada, com profissionais semiqualificados. De início, as 19 escolas instaladas, funcionaram de maneira precária para a realização das oficinas, tendo um corpo docente despreparado, pois muitos professores tinham somente a formação primária, com pouca noção do que deveriam lecionar no ensino profissional.

A principal atividade das Escolas Aprendizes e Artífices era a formação pelo ensino prático e conhecimentos específicos necessários aos menores que desejassem aprender um ofício nas oficinas destinadas para esse fim, atendendo sempre que possível às especialidades das indústrias locais. Entretanto a falta de condições estruturais comprometeu de início o papel a ser desempenhado por essas escolas, como afirma Frigotto

No início havia excessiva liberdade conferida pelo programa educativo aos diretores, bem como o despreparo dos mestres, e as escolas constituíam-se em espaço de qualificação de uma mão-de-obra que previam cursos de duração e intensidades variadas. Isso acarretou um mau funcionamento das escolas, tornando-as simples escolas primárias, onde os alunos aprendiam alguns trabalhos manuais. (2006, p. 31). 
Nos primeiros anos de funcionamento, apesar das Escolas Aprendizes e Artífices apresentarem poucos avanços no que diz respeito a sua filosofia e pedagogia, por outro lado, a rede de escolas trouxe uma grande novidade em relação à estrutura do ensino, constituindo-se o primeiro sistema educacional de abrangência nacional. (CUNHA apud FRIGOTTO, 2006, p. 35).

As décadas de 30 e 40 são marcadas por grandes transformações políticas, econômicas e educacionais na sociedade. A economia brasileira altera definitivamente o seu eixo, passando da atividade de agroexportação para a industrial. É nesse período da Era Vargas ou Estado Novo (1930 a 1945) que o Brasil passa por um processo de industrialização e modernização das relações de produção exigindo um posicionamento mais efetivo das camadas dirigentes em relação à educação nacional.

Assim, em 1930, as Escolas de Aprendizes e Artífices são substituídas pelos Liceus Industriais, embora os objetivos iniciais continuassem os mesmos. Uma década depois, em 1942, são criadas as Escolas Industriais e Técnicas, que ofereciam formação profissional em nível equivalente ao do secundário. Desse período em diante, começa o processo de vinculação do ensino industrial à estrutura do ensino como um todo, tendo em vista que os alunos advindos dos cursos técnicos estavam aptos a ingressar no ensino superior em área equivalente a sua formação.

Wanderley (2009) relata que somente no Estado Novo é que os diversos segmentos da educação profissional tiveram uma regulamentação, por meio de uma série de leis e decretos que contemplavam a organização do ensino superior, médio, secundário e profissional. Nesse contexto, dentro das reformas educacionais que atingiram o ensino profissional destacam-se a Reforma Francisco Campos e a Reforma Capanema, na qual implantou-se uma série de Decretos-Leis promulgadas no período de 1942 a 1946.

Em 1959, as Escolas Industriais e Técnicas passam à categoria de autarquias e a ser denominadas de Escolas Técnicas Federais. Com autonomia didática e administrativa, as Escolas Técnicas Federais intensificam a formação de técnicos, mão de obra indispensável ao processo de industrialização do Brasil.

Em 20 de dezembro de 1961, é promulgada a Lei de Diretrizes e Bases da Educação Nacional (LDB), Lei $n^{\circ} 4.024 / 61$, que abarcou todos os graus e modalidades de ensino, especialmente, no que se refere ao ensino profissional.

Oliveira (2012) aponta que, apesar das contradições refletidas na Lei n 4.024/61, é pela primeira vez que uma legislação envolve todos os níveis de modalidades de ensino e dá plena equivalência entre os cursos acadêmicos e os cursos profissionalizantes de mesmo nível, sem necessidade de adaptação, pondo fim à dualidade de ensino. No entanto, na prática, o autor enfatiza que,

os currículos se encarregam de mantê-la, pois a vertente propedêutica continuou privilegiando os conteúdos exigidos no acesso ao ensino superior, e os cursos profissionalizantes seguiram privilegiando os conteúdos vinculados às necessidades imediatas dos setores produtivos. Por outro lado, a LDB proporcionava a liberdade de atuação da iniciativa privada na educação e até promove incentivos e isenções. (OLIVEIRA, 2012, p. 50). 
A partir de 1964, com a instalação do regime militar, a educação no Brasil passou por um momento crítico. O período ditatorial, que perdurou duas décadas, foi marcado por uma série de reformas efetuadas em todos os níveis de ensino, que em termos educacionais, causou um retrocesso. Este período foi evidenciado pelo autoritarismo, repressão, privatização de ensino, exclusão das classes populares, institucionalização do ensino profissionalizante, tecnicismo pedagógico e desmobilização da categoria do magistério.

Para Saviani (1996), a Lei $n^{\circ}$ 5.692, de 11 de agosto de 1971, completa um ciclo de reformas educacionais com o objetivo de ajustar a educação brasileira à ruptura política perpetrada pelo golpe militar de 1964. Para tanto, tal ruptura política é uma exigência para a manutenção da ordem socioeconômica, compreendendo assim, que essa continuidade se reflita no âmbito educacional.

Paralelamente, as escolas técnicas federais se consolidavam, respectivamente, nas vertentes industrial e agropecuária, através de cursos demandados pelo modelo de desenvolvimento econômico. Além do mais, as escolas técnicas federais passaram a facilitar o acesso da classe média à universidade, enquanto a rede estadual de ensino ofertava um ensino profissionalizante fraco e desvinculado da realidade do mercado de trabalho. As vagas nas escolas técnicas federais eram muito disputadas, tendo em vista o elevado nível de qualidade e a oportunidade de fazer um ensino médio gratuito, além de dar possibilidades de ingresso à universidade.

A partir de 1978, inicia o processo de transformação das Escolas Técnicas Federais em Centros Federais de Educação Tecnológica (CEFETs), através da Lei n 6.545/78, instituições criadas para atuarem em nível mais elevado de formação profissional, exigência cada vez mais presente em função do padrão de produção, podendo formar engenheiros de operação e tecnólogos, reafirmando sua vinculação com o mundo do trabalho.

Na prática essa mudança acontece com a criação da Lei Nº 8.948, de 8 de dezembro de 1994, que institui no país o Sistema Nacional de Educação Tecnológica e transforma as Escolas Técnicas Federais em CEFETs, agora com abrangência nacional e de forma gradativa. Nesse período a rede ganha uma universidade tecnológica, a Universidade Tecnológica Federal do Paraná (UTFPR) e os CEFETs passam a agregar o ensino superior à oferta da educação profissional técnica de nível médio.

Em 20 de dezembro de 1996, a Lei de Diretrizes e Bases da Educação Nacional (LDB), sob o n 9.394, é aprovada, e no ano seguinte, o Decreto Federal n².208, de 17 de abril de 1997, regulamenta os artigos da LDB que tratam especificamente da educação profissional. Entretanto, esta modalidade é tratada à parte, não estando constituída dentro da estrutura regular de ensino, mesmo que o parágrafo $2^{\circ}$ do artigo 36 da seção IV do Capítulo II, deixe evidente que "o ensino médio, atendida a formação geral do educando, poderá prepará-lo para o exercício de profissões técnicas." (BRASIL, 1996).

De acordo com Frigotto (2006), apesar de apresentar um capítulo específico para a Educação Profissional, a nova LDB não cumpria as finalidades de uma Lei de Diretrizes e Bases, sendo que apenas apontava diretrizes gerais. Desta forma, a legislação para a educação profissional foi organizada gradativamente a partir do Decreto $n^{\circ} 2.208 / 97$, pelo Parecer do Conselho Nacional de Educação/Câmara de Educação Básica (CNE/CEB) nº 16/99 e Resolução n 04/99 CNE/CEB. Para a rede federal de educação tecnológica, a reforma da educação profissional foi implantada segundo as determinações da Portaria $\mathrm{n}^{\circ}$ $646 / 97$. 
O Decreto Federal $n^{\circ} 2.208 / 97$, é criado para regulamentar os artigos 39 a 42 da LDB, que trata sobre a educação profissional, até então não regulamentada. Assim a educação profissional é dividida em três níveis: básico, destinado à qualificação, requalificação e reprofissionalização dos trabalhadores, independente de escolaridade prévia; técnico, destinado a proporcionar habilitação profissional a alunos matriculados ou egressos do ensino médio; e tecnológico, correspondente a cursos de nível superior na área de tecnológica, destinados a egressos do ensino médio e técnico (BRASIL, 1997, art. 3º).

Além dos níveis, o Decreto define outras modificações para a educação profissional, como o currículo do ensino médio técnico que passa a ser organizado por disciplinas, agrupadas por áreas e setores da economia e sob a forma de módulos e a elaboração de suas diretrizes curriculares deverá levar em conta estudos de identificação do perfil de competências necessárias à atividade requerida, ouvidos os setores interessados, inclusive trabalhadores e empregadores. (BRASIL, 1997).

Em 1999, o processo de transformação das Escolas Técnicas e Agrotécnicas Federais em Centros Federais de Educação Tecnológica, iniciado em 1978, é retomado. Nessa configuração, os CEFETs tem autonomia para promover a implantação de cursos em todos os níveis da educação profissional e tecnológica, abrindo caminho para que as Escolas Agrotécnicas Federais sejam integradas nesse processo.

Mais adiante, o Decreto $n^{\circ} 2.208 / 97$ é revogado pelo Decreto $n^{\circ} 5.154$, de 23 de julho de 2004, que conforme Frigotto (2006) a única alteração que este Decreto trouxe foi o aumento da flexibilidade da articulação entre a educação profissional de nível técnico e o ensino médio, acrescentando a articulação na forma integrada às demais já existentes no decreto anterior. Assim, as articulações nas formas subsequente e concomitante, vem comtemplar a regulamentação do artigo 36 da LDB que possibilita o complemento profissionalizante ainda no ensino médio.

No pensamento de Oliveira (2012) o Decreto 5.124/04 buscou restabelecer os princípios norteadores de uma política de educação profissional articulada com a educação básica, tanto como um direito das pessoas quanto associado à necessidade do país.

A partir da segunda metade governo de Luiz Inácio Lula da Silva, políticas mais contundentes referentes à educação profissional e tecnológica foram retomadas. Primeiramente, destaca-se a implantação do ensino médio integrado, uma perspectiva consistente para construção teórico-prática de uma educação tecnológica que corresponda à preparação do educando para a compreensão dos fundamentos científico-tecnológicos, sócio históricos e culturais da produção moderna.

Conforme Oliveira (2012) é a partir dos meados dos anos 2000, que as políticas públicas destinadas à educação profissional são evidenciadas com a expansão da rede federal de educação profissional. É neste período que a ideia de expansão começa a se consolidar de maneira mais contundente, ou seja, a partir de uma nova configuração para a rede federal de educação profissional, com base na transformação dos CEFETs, nas Escolas Técnicas e Agrotécnicas Federais e algumas escolas vinculadas às universidades federais, em Institutos Federais. 


\section{OS INSTITUTOS FEDERAIS DE EDUCAÇÃO, CIÊNCIA E TECNOLOGIA: AVANÇOS E DESAFIOS}

Em continuidade ao processo de expansão da rede federal de educação profissional, o Governo Lula, em 2008, promulga a Lei n 11.892, de 29 de dezembro de 2008, que dispõe sobre a instituição da Rede Federal de Educação Profissional, Científica e Tecnológica e criação dos Institutos Federais de Educação, Ciência e Tecnologia. Sua intenção é compor uma estrutura abrangente voltada para o atendimento às demandas sociais e educacionais nos territórios.

Entretanto, é importante destacar que esse processo iniciou um pouco antes, quando o Decreto $n^{\circ}$ 6.095, de 24 de abril de 2007, é assinado pelo Presidente Lula. Este foi o primeiro dispositivo legal que tratou sobre a criação dos Institutos Federais de Educação, Ciência e Tecnologia. O Decreto estabelece diretrizes para o processo de integração de instituições federais de educação tecnológica, para fins de constituições dos Institutos Federais no âmbito da Rede Federal de Educação Tecnológica. (BRASIL, 2007b).

Em 12 de dezembro de 2007, o Ministério da Educação emitiu a Chamada Pública MEC/ SETEC 02/2007 com o objetivo de acolher propostas de composições de Institutos Federais de Educação, Ciência e Tecnologia, a ser apresentado pelos estados da federação através de suas instituições representadas, num prazo de 90 dias.

0 resultado da Chamada Pública foi apresentado em 31 de março de 2008 através da Portaria MEC/SETEC No 116. A relação das propostas aprovadas no processo de seleção de subsidiaram a elaboração do Projeto de Lei de criação dos Institutos Federais de Educação, Ciência e Tecnologia. 0 artigo $2^{\circ}$ destaca que "Os Institutos Federais do Acre, do Amapá, de Brasília, do Mato Grosso do Sul e de Rondônia serão implantados a partir da transformação das respectivas Escolas Técnicas Federais, criadas nos termos da Lei n. ${ }^{0} 11.534$, de 25 de outubro de 2007. (BRASIL, 2008a).

Em julho de 2008, o governo federal apresenta ao Congresso Nacional o Projeto de Lei 3.775 que propõe a instituição da Rede Federal de Educação Profissional, Ciência e Tecnológica e a criação dos Institutos Federais de Educação, Ciência e Tecnologia. Assim, a Lei 11.892 é aprovada no Congresso Nacional, e entra em vigor em 29 de dezembro de 2008 (OTRANTO, 2011).

Com a instituição da Rede Federal de Educação Profissional e Tecnológica foram criados 38 Institutos Federais de Educação, Ciência e Tecnologia, como forma de dar respostas às demandas crescentes na formação profissional e à necessidade de maior difusão de conhecimentos científicos e tecnológicos. Desta forma, os Institutos Federais, se tornaram referência na rede e todas as demais instituições criadas a partir deles, passaram a seguir o seu modelo de organização (OTRANTO, 2011).

Para Otranto (2011) a Lei 11.892/08 integrou uma série de medidas normativas que tinha como objetivo a concretização do Plano de Desenvolvimento da Escola (PDE) do Governo Lula, este sendo um dos mais significativos componentes educacionais do Plano de Aceleração do Crescimento (PAC). Dentre essas medidas destacaram-se: O Programa Nacional de Integração da Educação Profissional com a Educação Básica na modalidade de Jovens e Adultos (PROEJA), o Programa Brasil Alfabetizado eo Programa de Expansão da RedeFederal deEducação Profissional.

Outro fato importante na trajetória da Educação Profissional a partir da ampliação da Rede Federal de Educação Profissional e Tecnológica é a chegada dos IFs no Distrito Federal e em estados da federação onde não existiam estruturas anteriores mais consolidadas, como os estados do Amapá, Acre, Rondônia, Mato Grosso do Sul e Brasília (DF). Alguns desses locais ainda estavam em processo de implantação ainda das antigas Escolas Técnicas Federais, mas que logo foram transformados em IFs, sendo as instituições mais novas da rede. 
Além dos Institutos Federais, integraram também a rede de educação profissional, as autarquias que não aderiram à transformação em IFs: os Centros Federais de Educação Tecnológica Celso Suckow da Fonseca - CEFET-RJ e de Minas Gerais - CEFET-MG, 24 escolas vinculadas às Universidades Federais e a Universidade Tecnológica Federal do Paraná (UTFPR).

Em relação às Escolas Agrotécnicas Federais, todas aderiramà proposta detransformação em campus dos IFs, apesar de algumas instituições serem centenárias na oferta de cursos técnicos de nível médio. Para as Escolas Agrotécnicas transformar-se em Instituto Federal significava a possibilidade de ofertar ensino superior. No entanto, existia a preocupação de perderem sua autonomia, tendo em vista que as Reitorias ficariam sob a responsabilidade dos CEFET's. (Otranto, 2011).

Resumidamente, com a Lei 11.892/08 foram criados 38 Institutos Federais de Educação, Ciência e Tecnologia, a partir da adesão de 75 instituições, dentre as 102 que optaram. Assim, os IFs foram compostos pelas 36 Escolas Agrotécnicas, 31 dos 33 Centros Federais de Educação Tecnológica e 8 das 32 Escolas Vinculadas.

Conforme Oliveira (2012), antes da criação dos Institutos Federais, a centralidade das discussões dentro da rede estava na sua função social no contexto da ampliação e no significado do ensino médio integrado, inclusive na modalidade de Educação de Jovens e Adultos (EJA). Com a chegada dos IFs essa centralidade se deslocou para as questões referente a estrutura administrativa, para a ocupação dos novos cargos criados e para a construção dos novos campi, inclusive das reitorias. Isso ocorrendo com muita pressa, reduzindo-se a ideia de construir escolas para a edificação de prédios maiores e mais estruturados. Assim, o objetivo central era que os novos campi entrassem em funcionamento de forma imediata.

Portanto, conforme prevê o artigo $2^{\circ}$ da Lei 11.892/08 os Institutos Federais tornamse instituições de educação superior, básica e profissional, pluricurriculares e multicampi, especializados na oferta de educação profissional e tecnológica nas diferentes modalidades de ensino, com base na conjugação de conhecimentos técnicos e tecnológicos com as suas práticas pedagógicos. Além do mais, para efeito de regulação, avaliação e supervisão das instituições e dos cursos de educação superior, os institutos federais são equiparados às universidades federais. (BRASIL, 2008b).

O grande desafio dessa rede é estabelecer critérios na definição das cidades-polo a serem implantados os diversos campi durante esse processo de expansão. A sua primeira fase de expansão, iniciada em 2006, tinha como objetivo implantar escolas federais de formação profissional e tecnológica em estados ainda desprovidos dessas instituições. Também esta fase, buscou atender as periferias de metrópoles e os municípios interioranos distantes dos centros urbanos, onde os cursos estivessem articulados com as potencialidades locais para a geração de emprego (MEC, 2010).

Em 2007, na segunda fase de expansão, procurou-se ampliar essa implantação com a criação de novas unidades. Para este período o governo utilizou uma frase que ficou muita conhecida dentro da rede: "Uma escola técnica em cada cidade-polo do país". Foi prevista assim, a implantação de 150 novas unidades de ensino, no intuito de criar 180 mil vagas para a educação profissional e tecnológica e uma projeção de vagas para que a rede federal de educação tecnológica atenda até 2010, 500 mil matrículas (MEC, 2010).

A política de expansão da Rede Federal de Educação Profissional e Tecnológica proposta pelo governo Lula com continuidade no governo de Dilma Rousseff ganhou grande repercussão quando essas políticas se ampliaram no âmbito de todo o território nacional. Como destaca Otranto: 
O Instituto Federal é, hoje, mais que um novo modelo institucional, é a expressão maior da atual política pública de educação profissional brasileira. Está produzindo mudanças altamente significativas na vida e na história das instituições que optaram por aderir à proposta governamental. (2010, p. 89-110).

Vale ressaltar, que este é foi projeto muito ambicioso e que necessita de um olhar mais detalhado sobre o impacto dessa expansão para os próximos anos. Principalmente, se considerarmos que a implantação de novos campi requer um diálogo intenso para o processo de interiorização e regionalização da educação profissional, tanto na esfera municipal como na esfera estadual e federal.

\section{OS INSTITUTOS FEDERAIS E A CONTRIBUIÇÃO PARA DESENVOLVIMENTO TERRITORIAL}

A implantação dos Institutos Federais está relacionada ao conjunto de políticas de governo voltadas para a educação profissional e tecnológica, tendo em seu bojo o compromisso com o desenvolvimento socioeconômico local e regional e um efetivo diálogo com outras políticas setoriais. Como política pública, a educação profissional e tecnológica abrange não somente oferta de cursos voltados para a formação do trabalhador, mas principalmente, assume o compromisso com o todo o campo social.

Molina (2006), afırma que as relações sociais constituintes das dimensões territoriais, são concomitantemente interativas e completivas. Elas não podem ser dissociadas. A educação não existe fora do território, assim como a cultura, a economia e todas as outras dimensões. A análise separada das relações sociais e dos territórios é uma forma de construir dicotomias. Essa relação deve ser analisada em sua complexidade, pois os territórios são espaços geográficos e políticos, onde os sujeitos sociais executam seus projetos de vida para o desenvolvimento.

$\mathrm{Na}$ análise de Molina, os territórios são formados no espaço geográfico por diferentes relações sociais. Neste sentido, entende o território como sendo:

o espaço apropriado por uma determinada relação social que o produz e o mantém a partir de uma forma de poder. Esse poder, como afirmado anteriormente, é concedido pela receptividade. 0 território é, ao mesmo tempo, uma convenção e uma confrontação. Exatamente porque o território possui limites, possui fronteiras, é um espaço de conflitualidades. (MOLINA, 2006, p. 33).

Ainda de acordo com o autor, as relações sociais são predominantemente produtoras de espaços fragmentados, divididos, unos, singulares, dicotomizados, fracionados, portanto, também conflitivos. Nesta concepção, o território é um espaço geográfico, assim como a região e o lugar, e possui as qualidades composicionais e completivas dos espaços.

O conceito de território deve ser compreendido como uma mediação entre o mundo e a sociedade nacional e local, e assumido como um conceito indispensável para a compreensão do funcionamento do mundo presente. Como destaca Milton Santos,

o território não é apenas o resultado da superposição de um conjunto de sistemas naturais e um conjunto de sistemas de coisas criadas pelo homem. O território é o chão e mais a população, isto é, uma identidade, o fato e o sentimento de pertencer àquilo que nos 
pertence. O território é a base do trabalho, da resistência, das trocas materiais e espirituais e da vida, sobre os quais ele influi. Quando se fala em território deve-se, pois, território usado, utilizado por uma dada população. (2013, p. 96).

Num contexto mais atual, o território se apresenta como uma arena em movimentos cada vez mais numerosos, onde a finança global impõe suas regras sobre a totalidade da vida social, ignorando as estruturas existentes e impondo novas estruturas. Numa dimensão territorial, considerando o surgimento de novos conjuntos ou agrupamentos, a partir do estabelecimento de uma norma comum, novos processos de regionalização, superpostos a outros já existentes, começam a se delinear. Para Arroyo e Santos (1997) são tentativas de construção de novas entidades regionais, baseadas em uma solidariedade organizacional obtida mediante a circulação, o intercâmbio e sua regulação, que se dá a partir de contiguidades e continuidade territoriais.

As novas propostas de regionalização, ocasionadas pelas mudanças ocorridas no cenário internacional, como o aparecimento de criação de zonas de livre comércio, uniões aduaneiras e mercados comuns a partir do agrupamento de países, também influenciam em termo de gestão e planejamento, o processo de regionalização através da proposição de políticas governamentais nos diversos campos de atuação, inclusive na educação profissional.

É neste sentido, portanto, que os Institutos Federais surgem, constituindo-se um espaço fundamental para a construção de novas propostas voltadas para a Educação Profissional e Tecnológica na busca de sintonia com as potencialidades de desenvolvimento local e regional. Eles surgem como autarquia de regime especial de base educacional humanísticotécnico-científica, encontrando na territorialidade e no modelo pedagógico elementos singulares para a definição de sua identidade. Assim, é importante destacar que:

É na compreensão dos aspectos essenciais dessa relação e na sedimentação do sentimento de pertencimento territorial que se torna possível subverter a submissão de identidades locais a uma global. Esse caminho passa necessariamente por uma educação que possibilite ao indivíduo o desenvolvimento de sua capacidade de gerar conhecimentos a partir de uma prática interativa com a realidade. (PACHECO, 2010).

Para Pacheco (2010) a estrutura multicampi e a definição do território de abrangência das ações dos Institutos Federais afirmam o compromisso de intervenção em suas respectivas regiões, ao identificar os problemas e propondo soluções técnicas e tecnológicas para o desenvolvimento sustentável com inclusão social. Segundo o autor, o território de abrangência das ações de um Instituto Federal é a Mesorregião, isto é, espaços geográficos com características socioeconômicas, políticas e culturais comuns, podendo ir além do limite em que se localiza quando se concebe sua atuação em rede.

Durante o período de transformação da Rede Federal de EPT, os Centros Federais de Educação Tecnológica (CEFET's), as escolas agrotécnicas federais e as escolas técnicas vinculadas às universidades saem de cena para dar lugar aos Institutos Federais de Educação, Ciência e Tecnologia com o desafio de dar continuidade a uma concepção de educação profissional pautada numa formação contextualizada, de conhecimentos, princípios e valores, que potencializam a ação humana na busca de caminhos de vida mais dignos. 
O desenvolvimento local e regional vem no bojo do conjunto de políticas públicas transpassam determinada região, mas não como o único meio desse processo de desenvolvimento, pois os Institutos Federais estão situados em determinada área geográfica e associados a projetos e programas mais amplos e globais. É preciso estabelecer o vínculo entre o local e o global e que suas ações conduzam à construção de uma cultura que supere a identidade global a partir de uma identidade sedimentada no sentimento de pertencimento territorial. (MEC, 2010, p. 22).

O conceito de território vem, portanto, permeando as políticas de educação profissional e tecnológica a partir da expansão dos Institutos Federais, reconhecendo o desenvolvimento local e regional como um espaço fundamental para a construção e democratização do conhecimento, como bem destaca as concepções e diretrizes do MEC:

a comunicação entre os Institutos Federais e seu território torna-se imprescindível na definição de rumos a ser construídos a partir de uma concepção endógena, sob o ponto de vista de projetos locais. Por outro lado, a proposta traz em seu bojo não o autoritarismo de implantação e implementação, mas a crença de que, ao entrar em contato com a cultura de território, ela altera-se a partir do processo interativo instaurado (MEC, 2010, p. 23).

Silva (2009) ao fazer uma análise sobre a Lei n 11.892/08, destaca também a questão da territorialidade na criação dos Institutos Federais. Na sua visão, um ponto primordial no processo de negociação dos institutos foi o limite geográfico dos estados da federação, ao considerar as mesorregiões socioeconômicas dos estados em razão da natureza da investigação dos institutos nas referidas regiões. A ideia era unificar ao máximo as diferentes autarquias de um mesmo estado, abarcando as identidades socioeconômicas de uma determinada região mantendo sua delimitação em área territorial contínua. Sobre esta Lei, Silva explicita que,

No inciso I do art. $6^{\circ}$, é ressaltada como finalidade dos institutos colaborar para o desenvolvimento local, regional e nacional e o parágrafo $3^{\circ}$ do art. $2^{\circ}$ coloca a área de atuação territorial dessa instituição como limite de abrangência de sua autonomia para criação e extinção de cursos. Esses dois trechos evidenciam a importância do território na concepção dos institutos federais e na definição dos limites de sua atuação, mas é preciso considerar que a noção de território é polissêmica. Pode-se, em uma concepção entendê-lo como espaço geográfico cujo conceito tem como referência as mesorregiões brasileiras. Neste sentido, pode-se afirmar que os institutos devem estar unificados em determinado território geográfico que constitui a soma de municípios que compõem as mesorregiões com instalações físicas dessas instituições (2009, p. 36).

Para Silva (2009), a esse conceito deve ser incorporado a concepção de território enquanto construção sociocultural que está vinculada a um determinado espaço e tempo. Ou seja, é um espaço formado por grupos sociais a partir da sua própria identidade e das relações que ocorrem entre si, num determinado tempo histórico. É preciso superar, portanto, a dimensão geográfica de território e concebê-lo como espaço de rede de relações sociais em permanente movimento, pois é no território que se efetiva o desenvolvimento local e regional na perspectiva de sustentabilidade, um dos preceitos fundamentais do trabalho dos IFs. 


\section{CONSIDERAÇÕES FINAIS}

Os resultados deste estudo, com destaque na relação entre os Institutos Federais e o desenvolvimento territorial, mostram a importância de garantir o direito à oferta de educação profissional e tecnológica, pública e de qualidade, articuladas com outras forças sociais da região, no enfrentamento das desigualdades regionais e sociais.

Éneste sentido, que os Institutos Federais buscam desenvolver a educação profissional e tecnológica como processo educativo e investigativo de geração e adaptação de soluções técnicas e tecnológicas às demandas sociais e peculiaridades regionais. A perspectiva de atuação dos IFs, está no atendimento dos arranjos produtivos locais, na qual a medida governamental relaciona-se a uma distribuição dos campi fundada numa dinâmica que possibilite "ouvir e articular as demandas do território nos quais essas instituições estão inseridas, com suas possiblidades científicas e tecnológicas, tendo como foco a melhoria da qualidade de vida, a inclusão social e a construção da cidadania. (SILVA, 2009).

Para Silva (2009, p. 44), o desenvolvimento de processos educativos que levem a geração de trabalho e renda em prol do desenvolvimento local consolida a construção de uma proposta de formação que conduza o educando a novas possibilidades de ampliação de suas capacidades educativas e cognitivas. Neste sentido, é importante que os IFs promovam o desenvolvimento territorial, por meio de soluções educacionais de ensino, pesquisa e extensão, permitindo, de maneira efetiva, o acesso gratuito e de qualidade à educação profissional em todas as regiões do Brasil.

A oferta de cursos nos diferentes níveis e modalidades de ensino precisa estar articulada com a vocação regional e as demandas trazidas pela comunidade local. Porém, é necessário planejar com cautela a implantação de novos cursos, especialmente quando vinculados a uma nova área ou eixo tecnológico, verificando as potencialidades do município, a estrutura de laboratórios e equipamentos, bem como, a contratação de novos professores para atender essa nova demanda.

Entretanto, na medida em que o processo de constituição dos IFs vai se consolidando no território brasileiro, novos desafios vão se apresentando, entre eles, a constituição de uma unidade institucional considerando as diferentes realidades regionais tão desiguais, principalmente em se tratando da implantação de novos campi.

Em contrapartida, quando esses desafios são superados, contribuem significativamente para o fortalecimento da instituição, qualificando-se como centro de referência no apoio à oferta do ensino público gratuito, assumindo assim, o compromisso com a inclusão e justiça social, cidadania, preservação do meio ambiente, desenvolvimento regional, e principalmente, o fortalecimento da gestão democrática.

\section{REFERÊNCIAS}

1. ARROYO, M.; SANTOS, M. Globalização, regionalização: a proposta do Mercosul. Caderno Técnico. 79 p. Brasília: SESI-DN, 1997.

2. BRASIL . Lei n. 8.948, de dezembro de 1994. Dispõe sobre a instituição do Sistema Nacional de Educação Tecnológica. Diário Oficial da União, 9 dez. 1994.

3. Lei $n^{\circ}$ 9.394, de 20 de dezembro de 1996. Lei de Diretrizes e Bases da Educação Nacional. Brasília, 1996.

4. Decreto n. 2.208 , de 17 de abril de 1997 . Regulamenta o parágrafo $2^{\circ} 2^{\circ}$ do art. 36 e os arts. 39 a 42 da Lei n 9.394, de 20 de dezembro de 1996. 
5. Ministério da Educação. Documento Base da Educação Profissional Técnica de Nível Médio Integrada ao Ensino Médio. Secretaria de Educação Profissional e Tecnológica. Brasília, 2007a.

6. Decreto Federal $n^{\circ}$ 6.095, de 24 de abril de 2007. Estabelece diretrizes para o processo de integração de instituições federais de educação tecnológica, para fins de constituição dos Institutos Federais de Educação, Ciência e Tecnologia - IFET, no âmbito da Rede Federal de Educação Tecnológica. Brasília, 2007b.

7. Lei $n^{\circ} 11.534$, de 25 de outubro de 2007. Dispõe sobre a criação de Escolas Técnicas e Agrotécnicas Federais e dá outras providências. Brasília, 2007c.

8. Portaria n. ${ }^{\circ} 116$ de 31 de março de 2008. Resultado da Chamada Pública Chamada Pública MEC/SETEC n. ${ }^{\circ}$ 002/2007, de 12 de dezembro de 2007. Brasília, 2008 a.

9. Lei $n^{\circ} 11.892$, de 29 de dezembro de 2008. Institui a Rede Federal de Educação Profissional, Ciência e Tecnológica, cria os Institutos Federais de Educação, Ciência e Tecnologia. Brasília, 2008b.

10. FRIGOTTO, G. et al. (Org.). Educação profissional e tecnológica: memórias, contradições e desafios. Campos Goytacazes, RJ: Essentia Editora, 2006.

11. GÜNTHER, H. Pesquisa qualitativa versus pesquisa quantitativa: esta é a questão. In Revista Psicologia: Teoria e Pesquisa, Brasília, vol. 22n, p. 201-210, maio-ago 2006.

12. LEFOSSE, M. Z. C. M., Educação Profissional e Tecnológica: as interfaces dos Institutos Federais. V EPEAL. Alagoas. 2010.

13. MINISTÉRIO DA EDUCAÇÃO (MEC). Um novo modelo em educação profissional e tecnológica: concepções e diretrizes. Secretaria de Educação Profissional e Tecnológica. Brasília, 2010.

14. MOLINA, M. C. et al. (org.). Educação do campo e pesquisa: questões para reflexão. Brasília: Ministério do Desenvolvimento Agrário, 2006.

15. OLIVEIRA. R.(Org.). Jovens, ensino médio e educação profissional: políticas públicas em debate. São Paulo: Papirus, 2012.

16. OTRANTO, C. R., Criação e implantação dos Institutos Federais de Educação, Ciência e Tecnologia. In: Revista RETTA (PPGEA/UFRRJ). Ano I, nº 1, jan-jun 2010. P.89-110.

17. A política de educação profissional do Governo Lula. Trabalho aprovado para apresentação na 34 ${ }^{\mathrm{a}}$ Reunião da ANPED, Natal: RN, 2011.

18. PACHECO, E., Os Institutos Federais: uma revolução na educação profissional e tecnológica, 2010.

19. SANTOS, M. Por uma outra globalização: do pensamento único à consciência universal. 23a ed. Rio de Janeiro: Record, 2001.

20. SAVIANI. Política e educação no Brasil: o papel do Congresso Nacional na legislação do ensino. 3 ed. Campinas, SP: Autores Associados, 1996.

21. SILVA, C. J. R. (Org.). Institutos Federais Lei 11.892, de 29/11/2008: comentários e reflexões. Natal, RN: IFRN, 2009.

22. WANDERLEY, R.G. Educação profissional no Brasil e seu sistema institucionallegal: concepções e reflexões. Revista E.T.C. Educação, Tecnologia e Cultura. Ano 7, Nº 06, jan/dez. 2009, Salvador: IFBA, 2009. 